\title{
Glucose Oxidase Modified Electrodes of Polyaniline and Poly (aniline-co- 2-anilinoethanol) as a Biosensor: A Comparative Study
}

Ali Keyhanpour, Seyed Mohammad Seyed Mohaghegh* and Ahmad Jamshidi

Iron Polymer and Petrochemical Institute, Tehran, Iran

\begin{abstract}
A simple technique is described for constructing a glucose sensor so that enzymes, glucose oxidase (GOD) was immobilized by cross-linking via glutaraldehyde $0.1 \%$ at $0.1 \mathrm{M}$ phosphate buffer with $7.0 \mathrm{pH}$ in a polyaniline and poly(aniline-co-2anilinoethanol) thin films, which were electrochemically deposited on a platinum plate in phosphate and acetate buffer. The results of EIS and SEM indicated the successful immobilization for enzymes in the polymers film. The maximum current response was observed for the electrodes at $\mathrm{pH} 7$ and potential $0.65 \mathrm{~V}$ (versus Ag/ $\mathrm{AgCl}$ ). The poly (aniline-co-2anilinoethanol)/GOD electrode gives high stability and fast response as compared to polyaniline/GOD electrode in amperometric measurements so results show that the poly (aniline-co 2anilinoethanol) electrode is more suitable for biological systems.
\end{abstract}

Keywords: Glucose oxidase; Poly (aniline-co-2anilinoethanol); Immobilization; Polyaniline; Biosensors

\section{Introduction}

Glucose is a bio-molecule that is known to play a variety of roles in the welfare of mankind. The development of amperometric glucose biosensors is extensively investigated research area because of its importance in the treatment of diabetes mellitus health care, food and environmental monitoring and process industries, etc [1-6]. To date, the most commonly used amperometric glucose sensors use the specific recognition of glucose oxidase (GOD). The determination of biological compounds with biosensors has several advantages, e.g. ease of manipulation, rapidity and simple pretreatment of samples and the establishment of analytical methods based on biosensors [7]. Conducting polymers have also found applications in amperometric enzyme electrodes with the intention to couple the electron transfer reaction between enzyme and electrode via the ramified conducting network of the polymer for example, polypyrrole [8], polyaniline [9,10], poly (o-anisidine) [11], poly (o-toluidine) [12] and etc. Among others, the poly-conjugated conducting polymers have been recently proposed for biosensing applications because of a number of favorable characteristics such as: (i) direct and easy deposition on sensor electrode by electrochemical oxidation of monomer, (ii) control of thickness and (iii) Redox conductivity [11]. Conducting polymers have attracted much interest as a suitable matrix for entrapment of enzymes [13,14] forming an enzyme electrode. These enzyme electrodes are a reliable, accurate and low-cost biosensors widely used in biomedical analysis. The immobilization of enzymes in electrode materials is achieved either by physical or chemical methods [15-18]. Immobilization of enzymes is under taken either for the purpose of basic research or for use in technical processes of commercial interests. Immobilization means that enzymes, while retaining their catalytic activity, is confined within a certain space or is bound to solid carriers or to one another. Immobilization of enzymes has several advantages. These are: (i) the stability of the enzyme by protecting the active material from deactivation; (ii) repeated use; (iii) significant reduction in the operation cost; (iv) easy separation and recovery of the enzymes. Advantages of immobilization of enzymes in conducting polymer by electro polymerization are an easy one-step procedure, accurate control of the polymer thickness via the electrical charge passed during the film formation process, localization of the electrochemical reaction exclusively on the electrode surface allowing precise modification of microelectrodes and surfaces of complex geometry and the possibility to build up multilayer structures. The immobilization of enzymes or proteins in such polymers can be achieved by several techniques like physical entrapment, chemical cross-linking and covalent coupling. The physical entrapment covalent coupling and other methods suffer from leaching problems of the enzyme $[19,20]$. However this problem can be significantly overcome by using chemical cross-linking method of immobilization [21-23] via glutaraldehyde. GOD has been the most frequently used molecular recognition element, due to its high binding specificity, high turnover rate and relatively high stability. GOD can selectively catalyze the oxidation of glucose in the presence of oxygen to form hydrogen peroxide $\left(\mathrm{H}_{2} \mathrm{O}_{2}\right)$, which can be electrochemically detected by using electrodes [e.g., platinum $(\mathrm{Pt})$ and gold $(\mathrm{Au})$ ] at potentials positive to around $+0.6 \mathrm{~V}$ ( $\mathrm{vs}$. $\mathrm{Ag} / \mathrm{AgCl}$ ). The reactions can be described as follows:

$$
\begin{aligned}
& \beta \text {-D-glucose }+\mathrm{O}_{2}+\mathrm{H}_{2} \mathrm{O} \longrightarrow \text { gluconic acid }+\mathrm{H}_{2} \mathrm{O}_{2} \\
& \text { And } \mathrm{H}_{2} \mathrm{O}_{2} \longrightarrow \mathrm{O}_{2}+2 \mathrm{H}^{+}+2 \mathrm{e}
\end{aligned}
$$

Since the production of $\mathrm{H}_{2} \mathrm{O}_{2}$ is directly proportional to the glucose concentration, the oxidation current of $\mathrm{H}_{2} \mathrm{O}_{2}$ can be used to determine glucose concentration indirectly [24,25].

\section{Experimental}

\section{Reagents}

The monomers aniline (Merck) and 2-anilinoethanol (Merck)

*Corresponding author: Seyed Mohammad Seyed Mohaghegh, Iron Polymer and Petrochemical Institute, P.O. Box: 14965-115, Tehran, Iran, Tel: 48662444; Fax: 44580026; E-mail: s.m.mohaghegh@ippi.ac.ir

Received October 23, 2011; Accepted January 13, 2012; Published January 16 2012

Citation: Keyhanpour A, Mohaghegh SMS, Jamshidi A (2012) Glucose Oxidase Modified Electrodes of Polyaniline and Poly (aniline-co-2-anilinoethanol) as a Biosensor: A Comparative Study. J Biosens Bioelectron 3:116. doi:10.4172/21556210.1000116

Copyright: (c) 2012 Keyhanpour A, et al. This is an open-access article distributed under the terms of the Creative Commons Attribution License, which permits unrestricted use, distribution, and reproduction in any medium, provided the original author and source are credited. 
Citation: Keyhanpour A, Mohaghegh SMS, Jamshidi A (2012) Glucose Oxidase Modified Electrodes of Polyaniline and Poly (aniline-co-2anilinoethanol) as a Biosensor: A Comparative Study. J Biosens Bioelectron 3:116. doi:10.4172/2155-6210.1000116

Page 2 of 7

were distilled twice before use. The thin films of polyaniline and poly (aniline-co-2-anilinoethanol) were synthesized electrochemically on platinum substrates under cyclic voltammetric conditions in a single compartment glass cell. A three electrode geometry was employed during the electrochemical polymerization in which a platinum substrate functioned as the working electrode $\left(0.4 \mathrm{~cm}^{2} \Downarrow 0.4 \mathrm{~cm}^{2}\right)$, a Pt rod as counter electrode and $\mathrm{Ag} / \mathrm{AgCl}$ as the reference electrode. The films were electropolymerized in aqueous solution containing $0.1 \mathrm{M}$ monomer(s) and $1 \mathrm{M} \mathrm{H}_{2} \mathrm{SO}_{4}$ (Merck) as electrolyte. Glucose oxidase (EC 1.1.3.4, $580 \mathrm{Umg}^{-1}$ protein, from Merck) and D- glucose were used without further purification and glucose solutions were stored overnight at room temperature before use. The GOD was immobilized by cross-linking via glutaraldehyde $(0.1 \%)$ (Merck) on films, thus restricting the leaching of the enzyme film. These films were left for 30 min and washed with phosphate and/or acetate buffer. Buffers including the $\mathrm{HAc}+\mathrm{NaAc}$ system and the $\mathrm{KH}_{2} \mathrm{PO}_{4}+\mathrm{Na}_{2} \mathrm{HPO}_{4}$ were always employed as supporting electrolyte. Then both enzyme electrodes were washed thoroughly with $0.1 \mathrm{M}$ phosphate buffer solution and stored at $4^{\circ} \mathrm{C}$. All solutions were made up with twice distilled water.

\section{Apparatus}

Amperometry, cyclic voltammetry $(\mathrm{CV})$ and Faradaic impedance spectroscopy measurements were performed with a $\mathrm{CHI} 660 \mathrm{~B}$ electrochemical workstation ( $\mathrm{CH}$ Instruments, USA) in a conventional three-electrode cell. Pt plate electrode was used as working electrode. An
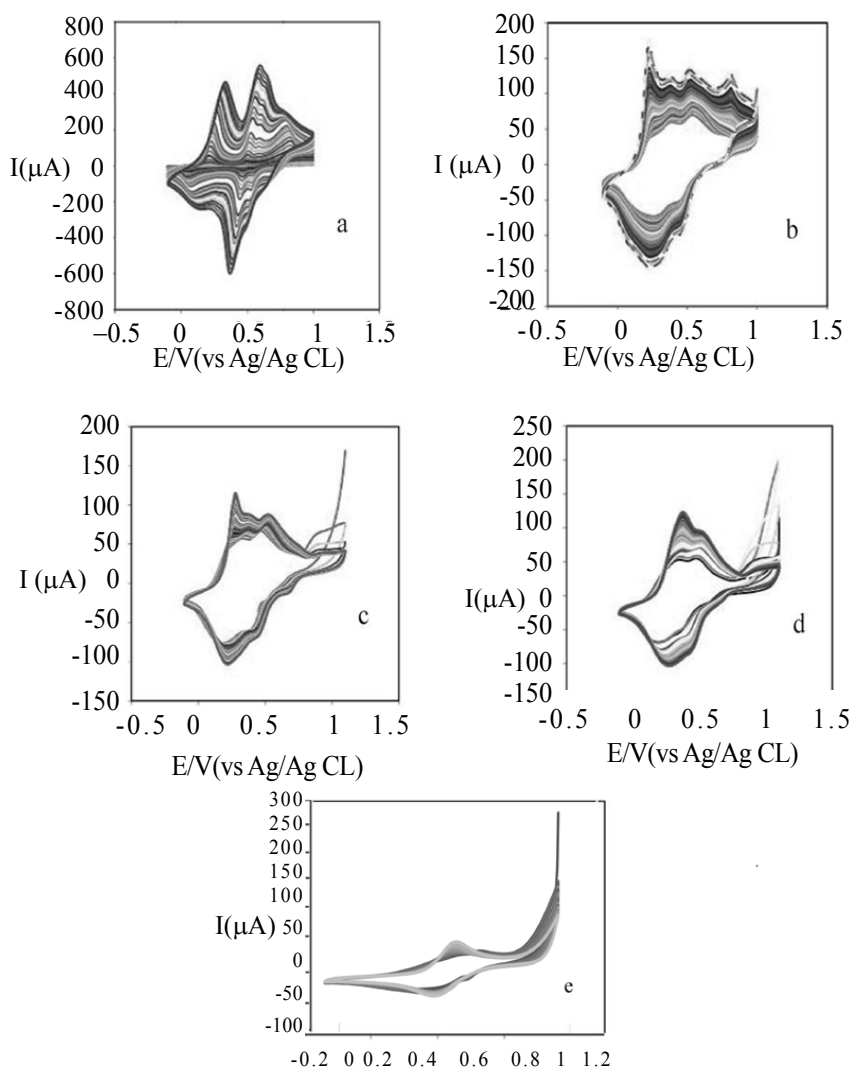

$\mathrm{E} / \mathrm{V}(\mathrm{vs} \mathrm{Ag} / \mathrm{Ag} \mathrm{CL})$

Figure 1: Cyclic voltammograms recorded during the synthesis of (a) polyaniline and the poly (aniline-co 2 anilinoethanol) with the volume percentage [(b) 90/10- (c) 85/15- (d) 50/50] and (e) Poly (2-anilinoethanol) films in aqueous solution of $\mathrm{H}_{2} \mathrm{SO}_{4}$ as electrolyte.
$\mathrm{Ag} / \mathrm{AgCl}$ electrode (saturated $\mathrm{KCl}$ ) and a Pt rod were used as reference and counter electrode, respectively. The scanning electron micrograph was recorded using JEOL, JSM-6360A SEM machine. The Faradaic impedance measurements were carried out in a background solution of in solution $0.5 \mathrm{M} \mathrm{Na}_{3} \mathrm{PO}_{4}$ at a normal potential. The alternating voltage was $5 \mathrm{mV}$ and the frequency range was $0.1 \mathrm{~Hz}$ to $100 \mathrm{kHz}$.

\section{Synthesis of polyaniline and copolymer of aniline/2- anilinoethanol}

Polyaniline and poly (aniline-co-2-anilinoethanol) film was synthesized from an aqueous solution of distilled $0.1 \mathrm{M}$ aniline and $0.1 \mathrm{M} 2$-anilinoethanol (Merck) and 1.0 M of sulfuric acid (Merck) using electrochemical deposition method. It was carried out by cyclic a voltammograms technique at $27^{\circ} \mathrm{C}$ in one compartment, threeelectrode glass cell. The platinum plate was used as working and $\mathrm{Pt}$ rod was used counter electrode and $\mathrm{Ag} / \mathrm{AgCl}$ was used as reference electrode. The electrolyte solution was prepared in distilled water. To control the thickness of the films, electro polymerization of this solution was carried out using a number of voltammetric cycle's: The first cycle was applied to induce the polymerization process and the following cycles to achieve the overall coating of the electrode. After synthesis, polymer coated electrodes were rinsed thoroughly in distilled water and dried in cold air and then use for subsequent characterization. For preparing of copolymers, We were used the volume percentage 90/10 aniline and 2-anilinoethanol, because there are two major factors in producing biosensors, the first high conductivity and the second reduced

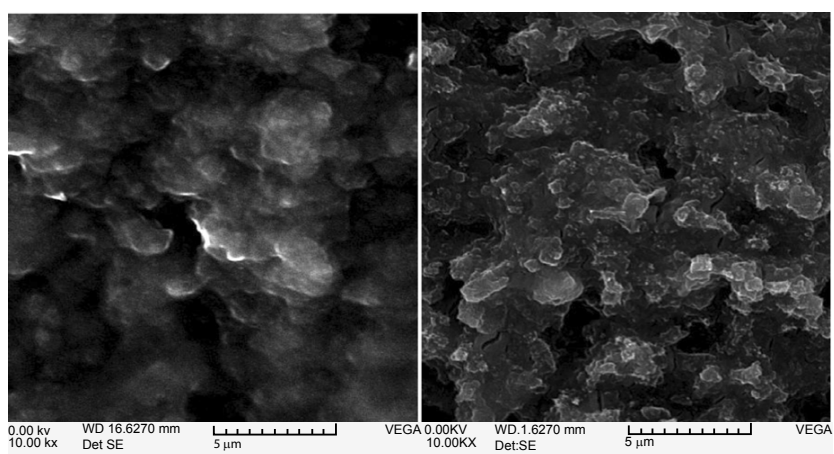

Figure 2: The scanning electron micrograph of synthesized (a) polyaniline and (b) poly (anilineco-2-anilinoethanol) with optimized electrochemical process parameters.

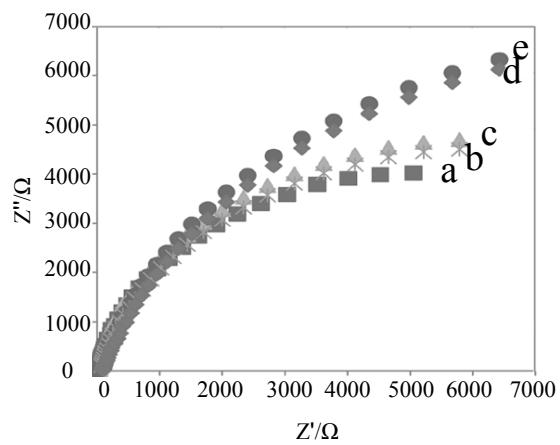

Figure 3: Nyquist plots of the electrochemical impedance spectroscopy (EIS) for (a) pt bare (b) polyaniline and (c) poly (aniline-co-2-anilinoethanol) and (d) polyaniline/GOD, (e) poly (anilineco-2-anilinoethanol) film. 
Citation: Keyhanpour A, Mohaghegh SMS, Jamshidi A (2012) Glucose Oxidase Modified Electrodes of Polyaniline and Poly (aniline-co-2anilinoethanol) as a Biosensor: A Comparative Study. J Biosens Bioelectron 3:116. doi:10.4172/2155-6210.1000116

Page 3 of 7

contact resistance between the metal electrodes and the polymer film. It is shown that with increase of 2-anilinoethanol in copolymer, conductivity and resistance are decreased, but the processability and adhesion are increased. Hydrophilic film polymer obtained has increased with increasing (2-anilinoethanol) content. Considering the figure 1 is observed with increasing monomer 2-anilinoethanol in copolymer, and the number of pair's peaks is reduced. This shows that poly (2-anilinoethanol) and poly (aniline-co-2-anilinoethanol) are formed [26]. The PANI films showed a typical redox response with three redox couples (Figure 1). The first responses occur without loss or gain of protons (leucoemeraldine/ emeraldine) and third redox electrochemical response involves protonation and deprotonation (emeraldine/pernigraniline) couples are due to the interconversion reactions of PANI upon varying the potential. The middle peaks can be related to the formation of quinones (mostly benzoquinone) as a consequence of a hydrolysis reaction in water [27].

\section{SEM studies polyaniline and poly (aniline-co-2- anilinoethanol)}

The scanning electron micrograph was recorded using JEOL, JSM6360A SEM machine. The SEM micrograph of synthesized polyaniline and poly (aniline-co-2-anilinoethanol) is shown in Figure 2. Poly (aniline-co-2-anilinoethanol) structure show higher uniformity and porosity than polyaniline structure, which is suitable for immobilization of biocomponent [28].

\section{Immobilization of GOD on poly (aniline-co-2-anilinoethanol)}

Conducting polyaniline and poly (aniline-co-2-anilinoethanol) films were prepared using cyclic voltammograms technique in a solution of $1 \mathrm{M}$ aniline, $1 \mathrm{M}$ 2-anilinoethanol and $1 \mathrm{M} \mathrm{H}_{2} \mathrm{SO}_{4}$. Pt plates were used as working electrodes and Pt rod was used as the counter electrode. The films were thoroughly washed with phosphate buffer prior to use. The enzyme solutions were prepared in $0.1 \mathrm{M}$ phosphate buffer $(\mathrm{pH}$ 7.0) with the working concentration of $20 \mathrm{U} / \mathrm{ml}$ for GOD. The enzyme GOD was immobilized by cross-linking via (1\%) glutaraldehyde on polyaniline and poly (aniline-co-2-anilinoethanol) films and left 30 min and then washed with phosphate and acetate buffer to remove any loosely bound enzyme. Because physical adsorption of an enzyme onto a solid although is probably the simplest way of preparing immobilized enzymes but the method relies on non-specific physical interaction between the enzyme protein and the surface of the matrix, brought about by mixing a concentrated solution of enzyme with the solid. In addition, because of the weak bonds involved, desorption of the protein resulting from changes in temperature, $\mathrm{pH}$, ionic strength or even the mere presence of substrate, is often observed. Another disadvantage is non-specific further adsorption of other proteins or other substances as the immobilized enzyme is used. This may alter the properties of the immobilized enzyme or, if the substance adsorbed is a substrate for the enzyme, the rate will probably decrease depending on the surface mobility of enzyme and substrate. But cross-linking an enzyme to it is both expensive and insufficient, as some of the protein material will inevitably be acting mainly as a support, resulting in relatively low enzymatic activity. Generally, cross-linking is best used in conjunction with one of the other methods.

\section{Faradaic impedance spectroscopy}

Impedance spectroscopy is an effective method to probe the features
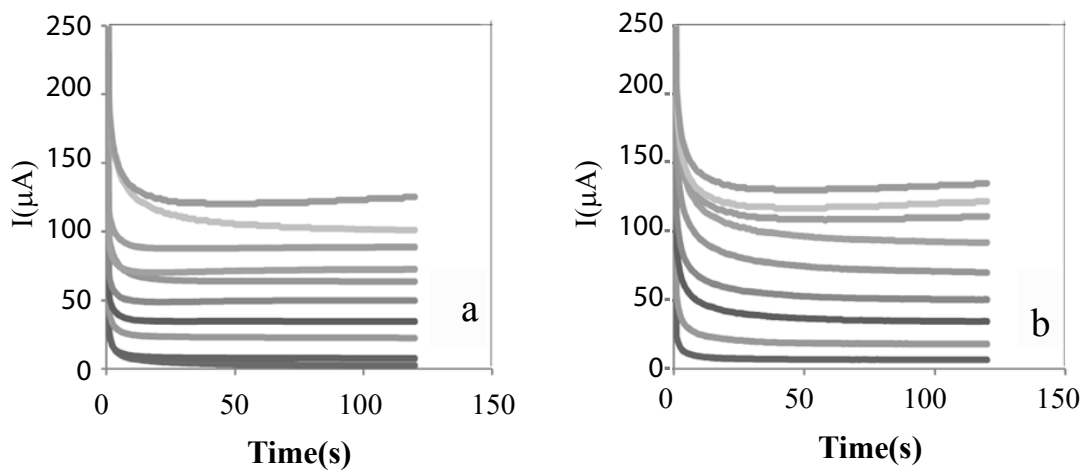

Figure 4: Current-time curves for the glucose oxidase electrode of (a) polyaniline and (b) poly (aniline-co-2-anilinoethanol) at 0.65V. Glucose solution (1) 1 mM, (2) 3 mM, (3) $5 \mathrm{mM}$, (4) $7 \mathrm{mM}$, (5) $10 \mathrm{mM}$, (6) $15 \mathrm{mM}$, (7) $20 \mathrm{mM}$, (8) $30 \mathrm{mM}$, (9) $40 \mathrm{mM}$ in 0.1M phosphate buffer, pH 7.
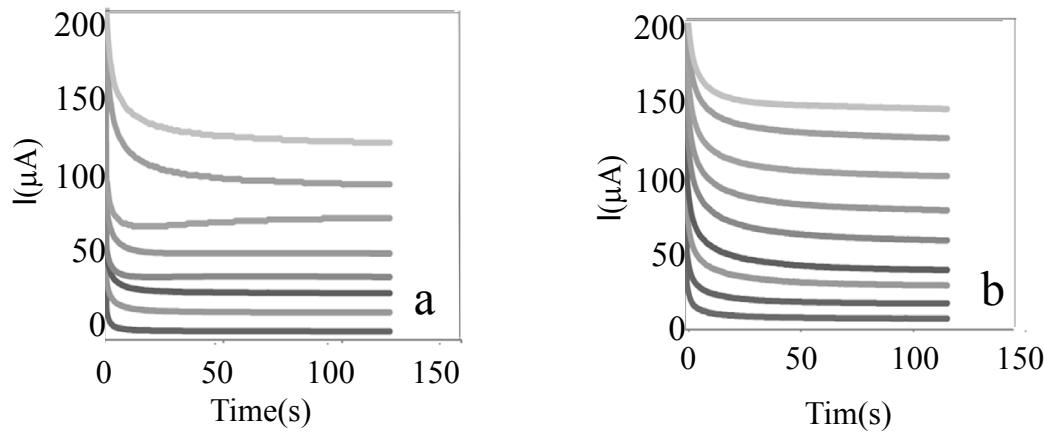

Figure 5: Current-time curves for the glucose oxidase electrode of (a) polyaniline and (b) poly (aniline-co-2-anilinoethanol) at $0.65 \mathrm{~V}$. Glucose solution (1) 1 mM, (2) 3 $\mathrm{mM}$, (3) $5 \mathrm{mM}$, (4) $7 \mathrm{mM}$, (5) $10 \mathrm{mM}$, (6) $15 \mathrm{mM}$, (7) $20 \mathrm{mM}$, (8) $30 \mathrm{mM}$,(9) $40 \mathrm{mM}$ in 0.1M acetate buffer, pH 7. 
Citation: Keyhanpour A, Mohaghegh SMS, Jamshidi A (2012) Glucose Oxidase Modified Electrodes of Polyaniline and Poly (aniline-co-2anilinoethanol) as a Biosensor: A Comparative Study. J Biosens Bioelectron 3:116. doi:10.4172/2155-6210.1000116

Page 4 of 7

of the surface modified electrodes. These studies were employed for modification of the electrode with individual and mixed components used for the fabrication of the biosensor. The complex impedance can be presented as the sum of the real Z' $(\omega)$ and imaginary Z" $(\omega)$, components that originate mainly from the resistance and capacitance of the cell, respectively. The general electronic equivalent scheme (Randles and Ershler model, inset of Figure 3, include the ohmic resistance of the electrolyte solution, $R_{s}$, resulting from the diffusion of ions from the bulk electrolyte to the electrode interface, the doublelayer capacitance, $C_{d l}$ and the electron-transfer resistance $R_{c t}$ that exists if a redox probe is present in the electrolyte solution. The electrontransfer resistance, $R_{c t}$ controls the electron-transfer kinetics of the redox probe at the electrode interface. From the shape of an impedance spectrum, the electron-transfer kinetics and diffusion characteristics can be extracted from spectra.

Figure 3 shows the Faradaic impedance spectra presented as Nyquist plots $\left(Z^{\prime}(\omega)\right.$ vs. $Z^{\prime \prime}(\omega)$ ) upon the modification of the electrodes with the enzyme in the solution $0.5 \mathrm{M} \mathrm{Na}_{3} \mathrm{PO}_{4}$. The bare $\mathrm{Pt}$ electrode exhibits (curve a) that is characteristics of the diffusionally limited electron-transfer process. After the immobilization of enzymes, GOD (curves $d$ and e) separately over the surface of the electrodes aniline and poly (aniline-co-2-anilinoethanol), which generates a hydrophobic insulating layer on the electrode, introduced a barrier to the interfacial resistance. Upon immobilization of the enzymes, the electron-transfer resistance further increased. This is due to the attachment of the enzymes that increases the extent of insulation of the conductive support by the hydrophobic protein layers and also which might be caused by the hindrance of the macromolecular structure of GOD to the electron-transfer [29,30]. As a result, the interfacial electron-transfer resistance gradually increases in their values upon the immobilization of the biocatalysts which also confirmed the successful immobilization of GOD.

In addition, Figure 3 Shows the Faradaic impedance spectra, presented as Nyquist plots $\left(Z^{\prime}(\omega)\right.$ vs. $\left.Z^{\prime \prime}(\omega)\right)$ upon the modification of the electrodes polyaniline and poly (aniline-co-2-anilinoethanol). The electron-transfer resistance decreased, due to the increase in the hydrophilic with increase in content of 2-anilinoethanol, making it easier for the electron transfer to take place. That confirmed the successful synthesis of poly (aniline-co-2anilinoethanol) film for the biosensor. The response current of the active device depends on the contact resistance between the metal electrodes and the polymer film [11].

\section{Current response of the polyaniline and poly(aniline-co-2 anilinoethanol) GOD electrodes}

The change in response current of the active device glucose oxidase is the parameter of interest for sensor applications. The response potential of the device depends on several factors such as 1-the contact resistance between the metal electrode and the polymer film, 2-the geometric factor of the film and 3-the film conductivity. The film conductivity is depends on several factors, such as analyte $\mathrm{pH}$, temperature, polymer film potential, substrate concentration and enzyme loading. The GOD was immobilized on electrochemically synthesized polyaniline and poly (aniline-co-2-anilinoethanol) film by cross-linking via glutaraldehyde. The potential-time relationship of polyaniline /GOD and poly (anilineco-2-anilinoethanol)/ GOD electrode when the current of the enzyme was set $0.65 \mathrm{~V}$ in phosphate and acetate buffer is as shown in figure 4 , figure 5 and figure 6 respectively.

\section{Determination of the kinetic constants}

The kinetic parameters, $\mathrm{K}_{\mathrm{m}}$ and $\mathrm{I}_{\max }$ values of the free and immobilized invertase were determined by measuring initial rates of the reaction with sucrose as substrate in acetate buffer $(3 \mathrm{mM}, \mathrm{pH} 7)$ at $35^{\circ} \mathrm{C}$. The $\mathrm{K}_{\mathrm{m}}$ and $\mathrm{I}_{\max }$ values for the free and immobilized invertase were calculated from Lineweaver-Burk plots by using the initial rate of the enzymatic reaction.

$$
\frac{1}{I}=\frac{K_{m}}{I_{\max }}\left(\frac{1}{[s]}\right)+\frac{1}{I_{\max }}
$$

Where $[\mathrm{S}]$ was the concentration of substrate, I and $I_{\max }$ represented the initial and maximum rate of reactions, respectively. $\mathrm{K}_{\mathrm{m}}$ was the Michaels constant. The value of $\mathrm{K}_{\mathrm{m}}$ depends on immobilization of enzyme and lesser the $\mathrm{K}_{\mathrm{m}}$ gives the faster response of the electrode to glucose [31,32] (Figure 7, Figure 8, Table 1).

\section{Effects of temperature value of the polyaniline and of the poly (aniline-co-2-anilinoethanol) GOD electrodes}

Solutions containing glucose may differ in temperature. It is important to understand how the electrochemical sensing performance of the two electrodes responds to the temperature changes. Our test solution was $0.1 \mathrm{M}$ phosphate buffer, $\mathrm{pH} 7$ and acetate buffer, $\mathrm{pH}$ 7 containing $3 \mathrm{mM}$ glucose. During the glucose measurements, the temperature of the solution was controlled. For each of the electrodes, there were a total of six measurements between 35 and $60^{\circ} \mathrm{C}$ with
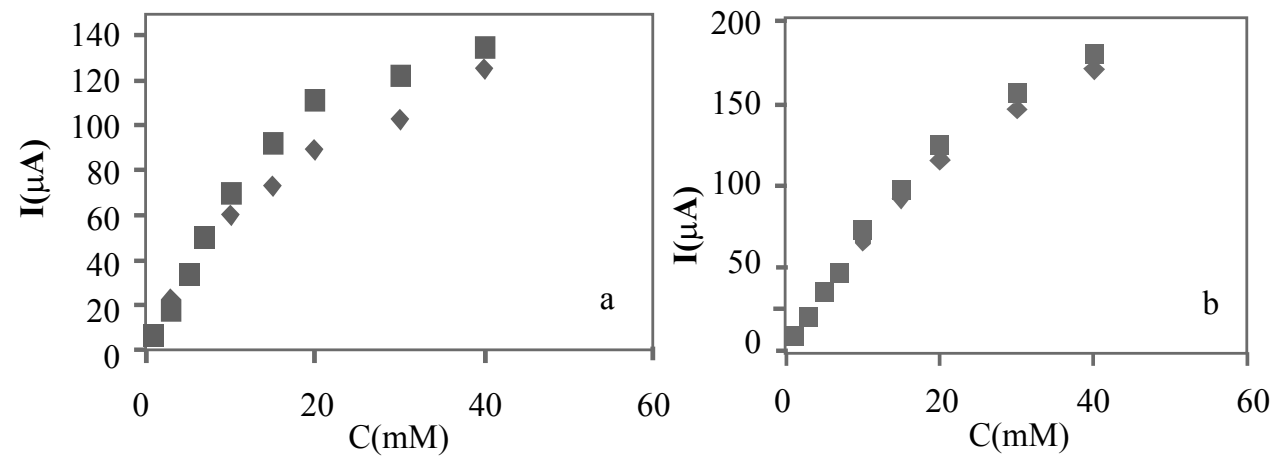

Figure 6: The relationship between response current and glucose concentration for the GOD electrode of polyaniline ( $\downarrow)$ and poly (aniline-co-2-anilinoethanol) (घ), in $0.1 \mathrm{M}$ phosphate buffer, $\mathrm{pH} 7$ (a) and in $0.1 \mathrm{M}$ acetate buffer, $\mathrm{pH} 7$ (b). 
Citation: Keyhanpour A, Mohaghegh SMS, Jamshidi A (2012) Glucose Oxidase Modified Electrodes of Polyaniline and Poly (aniline-co-2anilinoethanol) as a Biosensor: A Comparative Study. J Biosens Bioelectron 3:116. doi:10.4172/2155-6210.1000116

Page 5 of 7

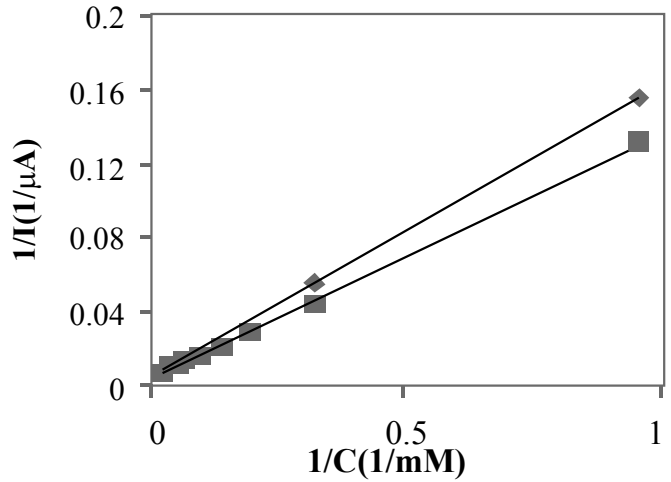

Figure 7: Determination of apparent Michaelis-Menten constant $(\mathrm{Km})$ for the GOD electrode of polyaniline $(\bullet)$ and poly (aniline-co-2-anilinoethanol) (घ) in $0.1 \mathrm{M}$ phosphate buffer, $\mathrm{pH} 7$

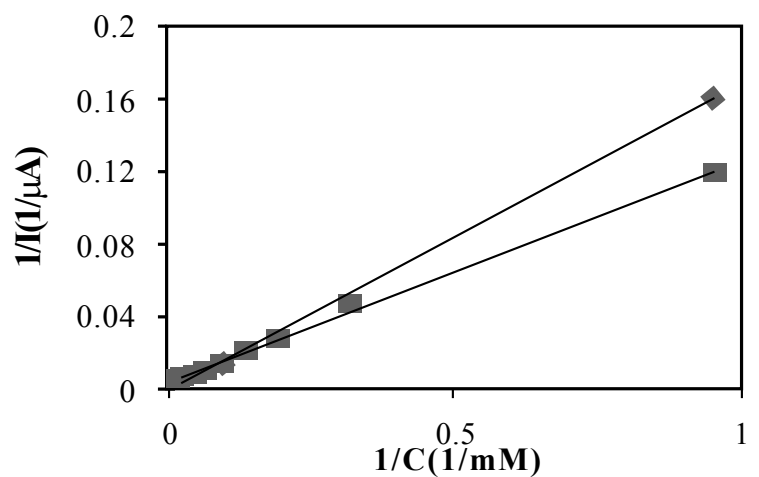

Figure 8: Determination of apparent Michaelis-Menten constant $(\mathrm{Km})$ for the GOD electrode of polyaniline ( $\bullet$ ) and poly (aniline-co-2-anilinoethanol) (घ) in $0.1 \mathrm{M}$ acetate buffer, $\mathrm{pH} 7$.

increments of $5^{\circ} \mathrm{C}$. Figure 9 shows the responses of the biosensors to the change of temperature. The response patterns of the two biosensors were analogous. The measured current signals were proportional to the temperature increase and reached their heights between 50 and $55^{\circ} \mathrm{C}$. The reasons for slower and faster reaction rates are because the temperature is directly proportional to the kinetic energy of the enzyme and surrounding molecules. Higher kinetic energy makes for a higher chance for the enzyme to bump into molecules that it will react with. According to the Arrhenius formula,

$$
\begin{aligned}
& \mathrm{I}(\mathrm{T})=\mathrm{I}_{0} \exp (-\mathrm{Ea} / \mathrm{RT}) \\
& \ln \mathrm{k}=\ln \mathrm{A}-(\mathrm{Ea} / \mathrm{RT}) \\
& \ln \mathrm{I}=\ln \mathrm{I}_{0}-\mathrm{Ea} / \mathrm{RT}
\end{aligned}
$$

where $k$ is the rate constant and $E$, the activation energy. Since the electrode surface areas, the quantity of the enzyme and the concentration of substrate are constant, the steady-state current is proportional to the rate constant $\mathrm{k}$ [33]. We replaced $\mathrm{k}$ with $\mathrm{I}$ in the Arrhenius formula. The relationships of $\log \mathrm{I}$ vs $1 / \mathrm{T}$ are plotted in Figure 11 and two straight lines were obtained. The activation energies were calculated from the slopes. The values of $\mathrm{E}$ of the polyaniline/GOD, for the phosphate buffer and acetate buffer are $45.3 \mathrm{~kJ} / \mathrm{mol}$ and $49.5 \mathrm{~kJ} / \mathrm{mol}$ and values of E poly (aniline-co-2anilinoethanol) GOD for the phosphate buffer and acetate buffer are $41.9 \mathrm{~kJ} / \mathrm{mol}$ and $46.2 \mathrm{~kJ} / \mathrm{mol}$, respectively From the above results, we can see that the activation energy of the glucose oxidation reaction under enzyme catalysis in phosphate buffer is smaller than that in acetate buffer. Therefore in acetate buffer, the energy required to enter transition state decreases, thereby decreasing the energy required to initiate the reaction and reaction time for reaching the steady-state current is shorter. In addition we can see that the activation energy of the glucose oxidation reaction under enzyme catalysis in of the poly (aniline-co-2-anilinoethanol)/GOD electrode is smaller than that in of the polyaniline/GOD electrode. Therefore in phosphate buffer was much preferred for use in amperometric measurements for poly (aniline-co-2anilinoethanol) glucose sensors (Figure 10).

\section{Effects of $\mathrm{pH}$ value of the polyaniline and of the poly (aniline- co-2-anilinoethanol)/GOD electrodes}

The $\mathrm{pH}$ of a solution can have several effects of the structure and activity of enzymes. Changes in $\mathrm{pH}$ may not only affect the shape of an enzyme but it may also change the shape or charge properties of the substrate so that either the substrate cannot bind to the active site or it cannot undergo catalysis. Immobilized enzyme-carrier complex, the enzyme molecules are subject to the effect of the micro-environment in the pores of the complex. Surface charges and other micro environmental effects can create a shift up or down of optimal $\mathrm{pH}$ of the enzyme activity [34]. The preparation of the test solution was similar to that of the temperature effect experiments, with the exception of the $\mathrm{pH}$ value controls. The effect of $\mathrm{pH}$ on the behavior of the enzyme electrodes was studied with $0.1 \mathrm{M}$ phosphate and acetate buffer solutions containing $3 \mathrm{mM}$ glucose. The steady-state currents at $0.65 \mathrm{~V}$, as a function of the $\mathrm{pH}$ values, are shown in Figure 11 . The electrochemical responses were quite good at $\mathrm{pH}$ ranging from 4.0-8.0, and the maximum current occurred at about $\mathrm{pH}$ 7. Bright and coworkers studied the $\mathrm{pH}$ dependence of solubilized GOD reactions and found a broad $\mathrm{pH}$ range of 4.0-8.0 with a maximum current of approximately $\mathrm{pH} 7$.

\section{Stability and lifetime of the polyaniline and of the poly} (aniline-co-2-anilinoethanol) electrode

Stability and lifetime of the GOD electrode response of the polyaniline and of the poly (anilineco-2anilinoethanol) have been studied. It shows excellent stability and response for 10 days (Figure 12). At the beginning of the test of lifetime, activity decreased rapidly. After a few days the modification electrode shows stable response. The poly (aniline-co-2-anilinoethanol)/GOD electrode gives high stability and fast response as compared to polyaniline/GOD electrode in amperometric measurements so results show that the poly(anilineco-2-anilinoethanol) electrode is more suitable for biological systems and for two electrode decreases current in the acetate buffer more than phosphate buffer so results show that phosphate buffer is more suitable for biological systems.

\begin{tabular}{|c|c|c|}
\hline \multicolumn{3}{|l|}{ Electrode } \\
\hline \multirow[b]{2}{*}{ Buffer } & Polyaniline & Poly (aniline-co-2anilinoethano) \\
\hline & $K_{m}(m M) I_{\max }(\mu A)$ & $\mathrm{K}_{\mathrm{m}}(\mathrm{mM}) \mathrm{I}_{\max }(\mu \mathrm{A})$ \\
\hline Phosphate & 31.75250 & 30.25325 \\
\hline Acetate & 46.5300 & 43.15350 \\
\hline
\end{tabular}

\section{Conclusion}

We have synthesises polyaniline and poly (aniline-co-

Table 1: Apparent Michaelis-Menten constant $\left(\mathrm{K}_{\mathrm{m}}\right)$ and maximum current $\left(\mathrm{I}_{\mathrm{H}}\right)$ of polyaniline and poly (aniline-co-2-anilino)/GOD films in $0.1 \mathrm{M}$ phosphate and 0.1 $\mathrm{M}$ acetate buffer at $\mathrm{pH} 7$. 
Citation: Keyhanpour A, Mohaghegh SMS, Jamshidi A (2012) Glucose Oxidase Modified Electrodes of Polyaniline and Poly (aniline-co-2anilinoethanol) as a Biosensor: A Comparative Study. J Biosens Bioelectron 3:116. doi:10.4172/2155-6210.1000116

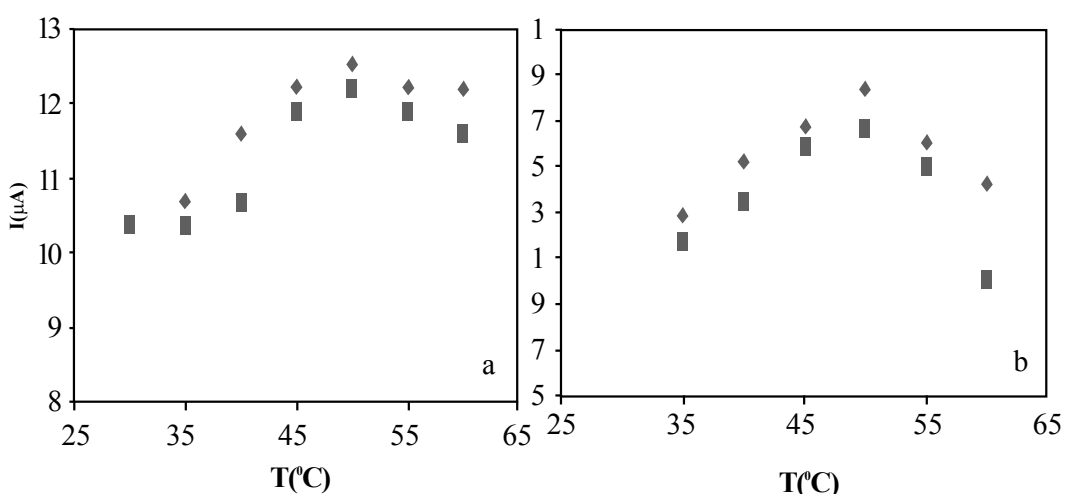

Figure 9: Effect of temperature on the responses (a) of the polyaniline/GOD and (b) of the poly (aniline-co-2-anilinoethanol) GOD, glucose sensors studied by ampero-

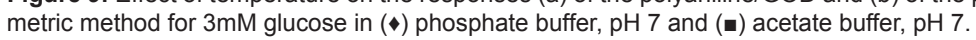
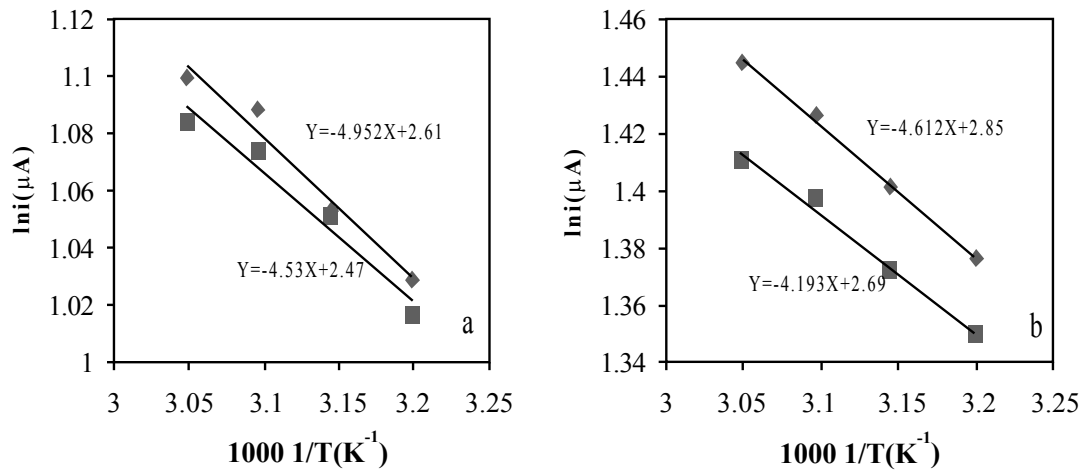

Figure 10: Plots of log I against I/T ( $\bullet$ phosphate buffer and $(\mathbf{\bullet})$ acetate buffer.
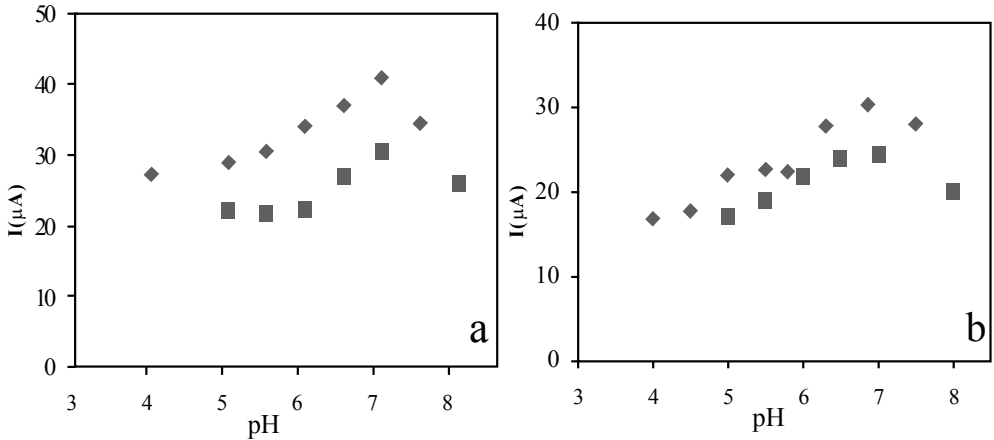

Figure 11: Effect of $\mathrm{pH}$ on the GOD electrode response (a) of the polyaniline and (b) of the poly (aniline-co- 2-anilinoethanol). The steady-state currents were measured at $0.65 \mathrm{~V}$ in a $3 \mathrm{mM}$ glucose solution in a $0.1 \mathrm{M}(\bullet)$ phosphate buffer and ( $\bullet$ ) acetate buffer, pH 7.
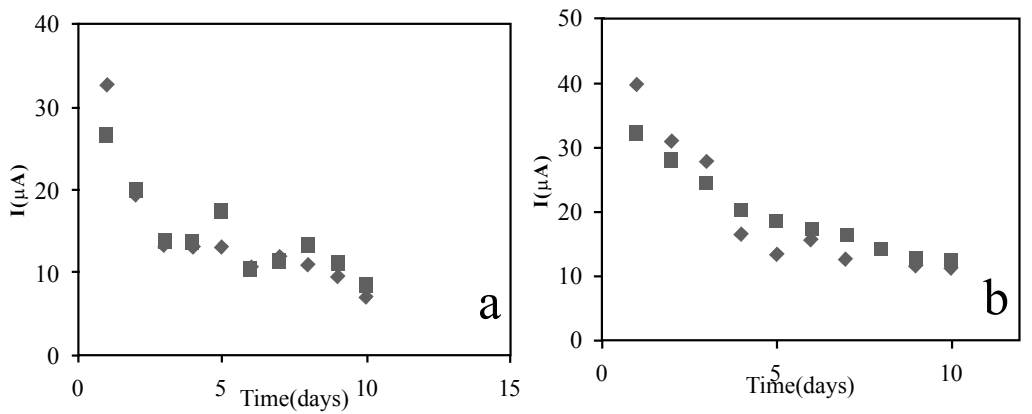

Figure 12: Stability of the polyaniline /GOD (a) and of the the poly(aniline-co- 2-anilinoethanol) GOD (b) electrode on storage in $(\downarrow) 0.1 \mathrm{M}$ phosphate buffer and $(\mathbf{\bullet}) 0.1 \mathrm{M}$ acetate buffer, $\mathrm{pH}$ 7at $6{ }^{\circ} \mathrm{C}$ 
Citation: Keyhanpour A, Mohaghegh SMS, Jamshidi A (2012) Glucose Oxidase Modified Electrodes of Polyaniline and Poly (aniline-co-2anilinoethanol) as a Biosensor: A Comparative Study. J Biosens Bioelectron 3:116. doi:10.4172/2155-6210.1000116

2anilinoethanol) glucose oxidase biosensor for the determination of glucose. The maximum current response for the polyaniline and poly (aniline-co-2-anilinoethanol) glucose oxidase electrode is at $\mathrm{pH} 7,0.65 \mathrm{~V}$ and $50^{\circ} \mathrm{C}$ in either phosphate buffer or acetate buffer. The poly (anilineco-2-anilinoethanol)/GOD electrode gives high stability and fast response as compared to polyaniline/GOD electrode in amperometric measurements. Results show that the poly (aniline-co-2-anilinoethanol) electrode is more suitable for biological systems. According to the rate constant and the activation energy measurements in both electrodes, the poly (aniline-co-2-anilinoethanol)/GOD electrode is much more preferable for use in amperometric measurements in both buffers than polyaniline/GOD electrode due to the comparative fast response.

\section{References}

1. Yoshimura K, Hozumi K (1996) Response characteristics of a glucose electrode with a sensing membrane prepared by plasma polymerization. J Microchem 53: 404-412.

2. Hikuma M, Kubo T, Yasuda T, Karube I, Suzuki S (1979) Amperometric determination of acetic acid with immobilized Trichosporon brassicae. Anal Chim Acta 109: 33-38.

3. Scheller F, Siegbahn N, Danielsson B, Mosbach K (1985) High-sensitivity enzyme thermistor determination of L-lactate by substrate recycling. Anal Chem 57: 1740-1743.

4. Bush DL, Rechnitz GA (1987) Monoclonal antibody biosensor for antigen monitoring. Anal Lett 20: 1781-1790.

5. Muramatsu H, Dicks JM, Tamiya E, Karube I (1987) Piezoelectric crystal biosensor modified with protein A for determination of immunoglobulins. Anal Chem 59: 2760-2763.

6. Sidwell JS, Rechnitz GA (1985) "Bananatrode" - An electrochemical biosensor for dompamine Biotechnology Lett 7: 419-422.

7. Wang HJ, Zhou CM, Peng F, Yu H (2007) Glucose biosensor based on platinum nanoparticles supported sulfonated-carbon nanotubes modified glassy carbon electrode. J Electrochem Sci 2: 508-516.

8. Cho JH, Shin MC, Kim HS (1996) Electrochemical adsorption of glucose oxidase onto polypyrrole film for the construction of a glucose biosensor. Sens Actuators B 30: 137-141.

9. Wang H, Zhou C, Jiahua L, Yu H, Peng F, et al. (2008) High sensitivity glucose biosensor based on $\mathrm{Pt}$ electrodeposition onto low-density aligned carbon nanotubes. J Int Electrochem Sci 3: 1258-1267.

10. Shaolin M, Huaiguo X, Bidong Q (1991) Bioelectrochemical responses of the polyaniline glucose oxidase electrode. Electroanal Chem 304: 7-16.

11. Savale PA, Shirsat MD (2009) Synthesis of poly(o-anisidine)/H(2)SO(4) film for the development of glucose biosensor. Appl Biochem Biotechnol 159: 299-309.

12. Borole DD, Kapadi UR, Mahulikar PP, Hundiwale DG (2004) Glucose oxidase electrodes of polyaniline, poly (o-toluidine) and their copolymer as a biosensor: a comparative study. Technologies Polym Adv Technol 15: 306-312.

13. Adeloju SB, Wallace GG (1996) Conducting polymers and the bioanalytical sciences: new tools for biomolecular communication. A review. Analyst 121: 699-703.

14. Sung WJ, Bae YH (2000) A glucose oxidase electrode based on electropolymerized conducting polymer with polyanion-enzyme conjugated dopant. Anal Chem 72: 2177-2181.

15. Fortier G, Belanger D (1991) Characterization of the biochemical behavior of glucose oxidase entrapped in a polypyrrole film. Biotechnol Bioeng 37: 854858 .

16. Uang YM, Chou TC (2003) Fabrication of glucose oxidase/polypyrrole biosensor by galvanostatic method in various $\mathrm{pH}$ aqueous solutions. Biosens Bioelectron 19: 141-147.

17. Iroh JO, Zhu Y, Shah K, Levine K, Rajagopalan R, et al. (2003) Electrochemica synthesis: a novel technique for processing multi-functional coatings. Progress In Organic Coatings 47: 365-375.
18. Sadki S, Schottland P, Brodie N, Sabouraud G (2000) The mechanisms of pyrrole electropolymerization. Chem Soc Rev 29: 283-293.

19. Wang H, Mu S (1999) Bioelectrochemical characteristics of cholesterol oxidase immobilized in a polyaniline film. Sensors and Actuators B 56: 22-30.

20. Yang H, Chung TD, Kim YT, Choi CA, Jun CH, et al. (2002) Glucose senso using a microfabricated electrode and electropolymerized bilayer films. Biosens Bioelectron 17: 251-259.

21. Guerrieri A, De Benedetto GE, Palmisano F, Zambonin PG (1998) Electrosynthesized non-conducting polymers as permselective membranes in amperometric enzyme electrodes: a glucose biosensor based on a cocrosslinked glucose oxidase/overoxidized polypyrrole bilayer. Biosens Bioelectron 13: 103-112.

22. Karalemas ID, Georgiou CA, Papastathopoulos DS (2000) Construction of a l-lysine biosensor by immobilizing lysine oxidase on a gold-poly (o-phenylenediamine) electrode. Talanta 53: 391-402.

23. Mizutani F, Sato Y, Hirata Y, Yabuki S (1998) High-throughput flow-injection analysis of glucose and glutamate in food and biological samples by using enzyme/polyion complex-bilayer membrane-based electrodes as the detectors. Biosens Bioelectron 13: 809-815.

24. Wingard LB Jr, Liu CC, Wolfson SK Jr, Yao SJ, Drash AL (1982) Potentiometric measurement of glucose concentration with an immobilized glucose oxidase/ catalase electrode. Diabetes Care 5: 199-202.

25. Wingard LD Jr. (1983) Federation proceedings. Federation of American Societies for Experimental Biology 42: 288.

26. Keyhanpour A, Seyed Mohaghegh S, Jamshidi A (2012) Iran polymer journal, in press.

27. Ansari R, Keivani MB (2006) Polyaniline conducting electroactive polymers thermal and environmental stability studies. E-J Chem 3: 202-217.

28. Patil S, Mahajan JR, More MA, Patil PP, Gosavi SW, et al. (1998) Polymer International 46: 99.

29. Shan D, Wang S, He Y, Xue H (2008) Amperometric glucose biosensor based on in situ electropolymerized polyaniline/poly(acrylonitrile-co-acrylic acid) composite film. Materials Science and Engineering C 28: 213-217.

30. Jeykumari DR, Narayanan SS (2008) Fabrication of bienzyme nanobiocomposite electrode using functionalized carbon nanotubes for biosensing applications. Biosens Bioelectron 23: 1686-1693.

31. Shu FR, Wilson GS (1965) Analytical Chemistry 240: 2209

32. Akundy GS, Rajagopalan R, Iroh JO (2002) Electrochemical deposition of polyaniline-polypyrrole composite coatings on aluminum. J Appl Polym Sci 83 1970-1977.

33. Chauve M, Mathis H, Huc D, Casanave D, Monot F, et al. (2010) Comparative kinetic analysis of two fungal beta-glucosidases. Biotechnol Biofuels $3: 3$.

34. Fabiano S, Tran-Minch C, Piro B, Dang LA, Pham MC, et al. (2002) Poly 3,4 ethylenedioxythiophene as an entrapment support for amperometric enzyme sensor. Materials Science \& Engineering C-Biomimetic and Supramolecular Systems 21: 61-67. 